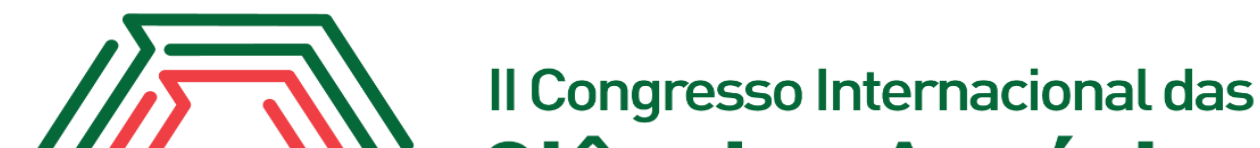 Ciências Agrárias COINTER - PDVAgro 2017
}

\section{ALTURA DE PLANTA DO CAPIM-CORRENTE EM FUNÇÃO DA ADUBAÇÃO FOSFATADA E NITROGENADA}

Edvaldo Alves de Moura ${ }^{1}$; Geovane Alves de Moura ${ }^{2}$; Guilherme Augusto dos Santos Sá ${ }^{3}$; Fábio Junno Simões de Morais Bezerra ${ }^{4}$; Mauricio Luiz de Mello Viera Leite ${ }^{5}$

\section{Introdução:}

A pecuária é uma atividade de grande relevância para o Semiárido de Pernambuco, pois é fonte de alimentos, renda e trabalho, embora esta região apresente uma elevada variabilidade na distribuição das chuvas. Neste cenário, a busca por plantas forrageiras adaptadas a essas condições climáticas é essencial para melhoria da produtividade da pecuária desta região.

O capim-corrente (Urochloa mosambicensis Hack. Daudy) é uma gramínea perene, com elevada adaptação ao clima quente, alta tolerância ao déficit hídrico, alta aceitabilidade e permite pastejo próximo ao nível do solo (LEITE et al., 2017; OLIVEIRA et al., 2016).

Esses aspectos reforçam a necessidade do conhecimento das características agronômicas do capim-corrente, pois são escassas as informações disponíveis na literatura sobre as características de crescimento dessa planta forrageira, principalmente nas condições do Semiárido brasileiro. Desse modo, objetivou-se avaliar a altura de planta do capimcorrente em função da adubação fosfatada e nitrogenada no Sertão pernambucano.

\footnotetext{
${ }^{1}$ Bacharelado em Agronomia, UFRPE-UAST, edvaldo10am@ hotmail.com

${ }^{2}$ Bacharelado em Agronomia, UFRPE-UAST, geovane-am@ hotmail.com

${ }^{3}$ Bacharelado em Agronomia, UFRPE-UAST, gyllerme@ hotmail.com

${ }^{4}$ Bacharelado em Zootecnia, UFRPE-UAST, fabio2014junno@ hotmail.com

${ }^{5}$ Professor Dr. Departamento de Agronomia, UFRPE-UAST, nopalea21@ yahoo.com.br
} 


\section{Fundamentação Teórica:}

Dentre as gramíneas utilizadas na alimentação animal no Semiárido brasileiro destacase o capim-corrente (Urocloa mosambicensis), que constitui uma das opções para a formação de pastagens cultivadas, enriquecimento de pastagens nativas e conservação de forragem, na forma de silagem e feno (LEITE et al., 2017).

Segundo MARTUSCELLO et al. (2009) e SOUSA et al. (2010), um dos maiores problemas no estabelecimento e na manutenção de pastagens nos solos brasileiros reside nos níveis extremamente baixos de fósforo disponível e total, bem como na alta capacidade de adsorção desse elemento. Os solos do Semiárido brasileiro, em sua maioria, contem baixos teores de fósforo, um dos elementos que mais limita a produtividade das forrageiras nessa região. O fósforo tem influência marcante no crescimento do sistema radicular e no perfilhamento das gramíneas forrageiras (VOLPE et al., 2008).

Desse modo, para a obtenção de produtividades elevadas das forrageiras nestes solos, torna-se necessária e imprescindível a adubação fosfatada, assim como a nitrogenada, que apresentam importante papel na morfogênese de plantas, promovendo aumento no metabolismo e nas taxas de reações enzimáticas (VITOR et al., 2009). As pesquisas divulgadas são consistentes ao apontar o fósforo e o nitrogênio como os principais elementos limitantes para a nutrição das plantas forrageiras.

Estudos envolvendo características morfogênicas e estruturais são importantes, pois fornecem informações detalhadas do crescimento vegetal e, se devidamente analisadas, podem propiciar estratégias de manejo que aumentam a eficiência do sistema solo-plantaanimal (PEREIRA et al., 2011).

\section{Metodologia:}

A pesquisa foi conduzida de 14 de outubro de 2014 a 08 de janeiro de 2015, em condições de campo, na UNIVERSIDADE FEDERAL RURAL DE PERNAMBUCO (UFRPE), Unidade Acadêmica de Serra Talhada (UAST), localizada sob as coordenadas geográficas $07^{\circ} 57^{\prime} 01^{\prime}$ ' S e $38^{\circ} 17^{\prime} 53^{\prime \prime} \mathrm{O}$, altitude de $523 \mathrm{~m}$, situada no município de Serra Talhada, Microrregião do Sertão do Pajeú, Mesorregião do Sertão Pernambucano.

A análise química do solo, coletado na UAST na profundidade de 0 a $20 \mathrm{~cm}$, foi realizada no Laboratório de Fertilidade dos Solos do Instituto Agronômico de Pernambuco 
(IPA) e revelou os seguintes teores de nutrientes: $\mathrm{pH}$ (água) $=6,80 ; \mathrm{P}($ extrator Mehlich $\mathrm{I})=$ $40,0 \mathrm{mg} \mathrm{dm}{ }^{-3} ; \mathrm{K}^{+}=0,45 \mathrm{cmol}_{\mathrm{c}} \mathrm{dm}^{-3} ; \mathrm{Ca}^{2+}=5,50 \mathrm{cmol}_{\mathrm{c}} \mathrm{dm}^{-3} ; \mathrm{Mg}^{2+}=1,6 \mathrm{cmol}_{\mathrm{c}} \mathrm{dm}^{-3} ; \mathrm{Al}=0,0$ $\mathrm{cmol}_{\mathrm{c}} \mathrm{dm}^{-3}$.

O solo, classificado como Luvissolo Crômico (EMBRAPA, 2013), utilizado no experimento, foi destorroado, submetido ao revolvimento para secagem ao ar, homogeneizado e acondicionado em vasos plásticos. Em cada vaso, com capacidade de 9,95 dm $\mathrm{dm}^{3}(22 \mathrm{~cm}$ de altura e $24 \mathrm{~cm}$ de diâmetro), disposto aleatoriamente sobre tijolos, colocou-se 7,2 kg de solo seco ao ar.

Duas mudas de capim-corrente, obtidas na UAST, foram plantadas em cada vaso, em 14 de outubro de 2014. Para evitar condição de estresse hídrico, nos primeiros 10 dias, após implantação do experimento, todas as plantas foram mantidas em solo sob condições de capacidade de campo. Após 30 dias do plantio, todas as plantas foram submetidas ao corte de uniformização, a $10 \mathrm{~cm}$ do solo.

A altura de planta foi avaliada obedecendo ao delineamento experimental inteiramente casualizado, no esquema fatorial $2 \times 2$ (presença e ausência de nitrogênio x presença e ausência de fósforo), com quatro repetições.

As fontes de nitrogênio e fósforo utilizadas foram o sulfato de amônio com $20 \%$ de $\mathrm{N}$ e o superfosfato simples com $18 \%$ de $\mathrm{P}_{2} \mathrm{O}_{5}$ solúvel em água, respectivamente. Utilizou-se uma dose de nitrogênio equivalente a $100 \mathrm{~kg} \mathrm{ha}^{-1}$ de $\mathrm{N}$ e uma dose de fósforo equivalente a $150 \mathrm{~kg}$ $\mathrm{ha}^{-1}$ de $\mathrm{P}_{2} \mathrm{O}_{5}$. O nitrogênio e o fósforo foram aplicados em cobertura, imediatamente após o corte de uniformização (14/11/2014). Durante todo o período experimental, os vasos foram mantidos livres de plantas invasoras.

A altura de planta do capim-corrente foi obtida através da medição com trena milimetrada a partir do nível do solo até a curvatura média da última folha completamente expandida, horizonte superior das folhas no dossel.

Os dados encontrados foram submetidos à análise de variância para verificação da significância dos tratamentos por meio do Teste F, ao nível de $1 \%$ de probabilidade. Sendo F significativo, as médias dos tratamentos foram comparadas pelo teste de Tukey, ao nível de $5 \%$ de probabilidade. Utilizou-se o programa estatístico R-project versão 2.13 .1 for windows. 


\section{Resultados e discussões:}

Verifica-se na Tabela 1 que não houve efeito significativo $(\mathrm{P}>0,10)$ para Altura de Planta (AP).

Tabela 1. Médias de altura de planta (AP) do capim-corrente, em função da presença ou ausência de nitrogênio e fósforo. Fonte: Própria

\begin{tabular}{ccc}
\hline $\begin{array}{c}\mathbf{N} \\
\left(\mathbf{k g ~ h a}^{\mathbf{- 1}}\right)\end{array}$ & $\begin{array}{c}\mathbf{P}_{\mathbf{2}} \mathbf{O}_{\mathbf{5}} \\
\left(\mathbf{k g ~ h a}^{-\mathbf{1}}\right)\end{array}$ & $\begin{array}{c}\mathbf{A P} \\
(\mathbf{c m})\end{array}$ \\
\hline 0 & 0 & 70,75 \\
0 & 150 & 59,00 \\
100 & 0 & 63,50 \\
100 & 150 & 78,75 \\
\hline Média & 68,00 \\
CV (\%) & 38,62 \\
\hline
\end{tabular}

$\mathrm{N}=$ nitrogênio; $\mathrm{P}_{2} \mathrm{O}_{5}=$ fósforo. $\mathrm{CV}=$ coeficiente de variação.

De acordo com os resultados apresentados, a altura de planta oscilou entre 78,75 e $59,00 \mathrm{~cm}$, com média de 68,00 cm (Tabela 1). MARANHÃO et al. (2010) observaram para o capim-braquiária, aos 28 dias pós corte, altura de planta de 16,5 a 32,3 cm, sem nitrogênio e 17,0 a 46,6 cm com $200 \mathrm{~kg} \mathrm{ha}^{-1} \mathrm{de} \mathrm{N}$, evidenciando-se a interação positiva desse macronutriente com a promoção de um maior crescimento das plantas forrageiras.

\section{Conclusão:}

A altura de planta do capim-corrente não sofreu diferenciação significativa para os níveis de adubação, fosfatada e nitrogenada, quando estudados os 30 primeiros dias do seu desenvolvimento.

\section{Referências:}

EMBRAPA - Empresa Brasileira de Pesquisa Agropecuária - Centro Nacional de Pesquisa de Solos. Sistema Brasileiro de Classificação de Solos. 3. ed. Brasília: Embrapa Solos, 2013. $353 \mathrm{p}$. 
LEITE, M. L. M. V.; LUCENA, L. R. R.; SÁ JUNIOR, E. H.; CRUZ, M. G. Estimativa da área foliar em Urochloa mosambicensis por dimensões lineares. Revista Agropecuária Técnica, v. 38, n. 1, p. 9-16, 2017.

MARANHÃO, C. M. A.; BONOMO, P.; PIRES, A. J. V.; COSTA, A. C. P. R.; MARTINS, G. C. F.; CARDOSO, E. O. Características produtivas do capim-braquiária submetido a intervalos de cortes e adubação nitrogenada durante três estações. Acta Scientiarum. Animal Sciences, v. 32, n. 4, p. 375-384, 2010.

MARTUSCELlO, J. A.; FONSECA, D. M.; MOREIRA, L. M.; RUPPIN, R. F.; CUNHA, D. N. F. V. Níveis críticos de fósforo no solo e na parte aérea no estabelecimento de capimelefante. Revista Brasileira de Zootecnia, v. 38, n. 10, p. 1878-1885, 2009.

OLIVEIRA, V. S. et al. Capacidade de suporte, produção e composição do dossel forrageiro de três gramíneas irrigadas ou não no período seco. Veterinária e Zootecnia. v. 23, n. 1, p. 88-92, 2016.

PEREIRA, O. G.; ROVETTA, R.; RIBEIRO, K. G.; SANTOS, M. E. R.; FONSECA, D. M.; CECON, P. R. Características morfogênicas e estruturais do capim-tifton 85 sob doses de nitrogênio e alturas de corte. Revista Brasileira de Zootecnia, v. 40, n. 9, p. 1870-1878, 2011.

SOUSA, R. S.; PIRES, A. J. V.; CARVALHO, G. G. P.; SILVA, F. F.; MAGALHÃES, A. F.; VELOSO, C. M. Composição química de capim-tanzânia adubado com nitrogênio e fósforo. Revista Brasileira de Zootecnia, v. 39, n. 6, p. 1200-1205, 2010.

VITOR, C. M. T.; FONSECA, D. M.; CÓSER, A. C.; MARTINS, C. E.; NASCIMENTO JÚNIOR, D.; RIBEIRO JÚNIOR, J. I. Produção de matéria seca e valor nutritivo de pastagem de capim-elefante sob irrigação e adubação nitrogenada. Revista Brasileira de Zootecnia, v. 38, n. 3, p. 435-442, 2009.

VOLPE, E.; MARCHETTI, M. E.; MACEDO, M. C. M.; LEMPP, B. Acúmulo de forragem e características do solo e da planta no estabelecimento de capim-massai com diferentes níveis de saturação por bases, fósforo e nitrogênio. Revista Brasileira de Zootecnia, v. 37, n. 2, p. 228-237, 2008. 